\title{
LA PROVISIÓN DE BENEFICIOS EN LA CATEDRAL DE LLEIDA DURANTE EL EPISCOPADO DE ANTONI CERDÀ (1449-1459)*
}

\author{
POR \\ AlBert CASSANYES ROIG ${ }^{1}$ \\ Universitat de Lleida
}

RESUMEN

La provisión de beneficios eclesiásticos fue una de las principales herramientas de los distintos poderes para colocar a sus allegados en las catedrales. El presente artículo estudia cómo y a quién se concedieron los beneficios en la catedral de Lleida durante la década en la que Antoni Cerdà fue obispo de la diócesis (1449-1459). A través de las Actas capitulares y de otra documentación complementaria, ha sido posible establecer la onomástica de los beneficiados en las distintas capillas y analizar los intereses que había detrás de su provisión.

PALABRAS CLAVE: beneficios eclesiásticos; cabildo catedralicio; Lleida; permuta de beneficios.

\section{THE CONCESSION OF BENEFITS IN THE CATHEDRAL OF LLEIDA DURING THE EPISCOPATE OF ANTONI CERDÀ (1449-1459)}

\begin{abstract}
The concession of ecclesiastical benefits was one of the most important tools of the diverse powers to place their intimates in cathedrals. This paper explores how and to whom the benefits within the cathedral of Lleida were granted in the decade during which Antoni Cerdà was the bishop of this diocese (1449-1459). Through the Chapter session minutes and other supplementary sources, it has been possible to determine the onomastic of the beneficiaries in the different chapels and to analyse the interests that lay behind their concession.
\end{abstract}

KEY WORDS: Ecclesiastical benefits; Cathedral Chapter; Lleida; Exchange of benefits.

Cómo CITAR ESTE ARTículo / CITATION: Cassanyes Roig, A. 2018. «La provisión de beneficios en la catedral de Lleida durante el episcopado de Antoni Cerdà (1449-1459)». Hispania Sacra 70, 141: 223-236. https://doi.org/10.3989/hs.2018.018

$\begin{array}{ll}\text { Recibido/Received } & \text { 07-04-2016 } \\ \text { Aceptado/Accepted } & \text { 16-05-2016 }\end{array}$

INTRODUCCIÓN

El beneficio eclesiástico era el conjunto de frutos, rentas y réditos que percibía un clérigo por el ejercicio de un oficio o el goce de una fundación en una institución eclesiástica, esencialmente - aunque no solo- una iglesia catedral o parroquial. Se trataba de una de las principales fuentes de

La elaboración del presente trabajo ha contado con el apoyo de la Secretaria d'Universitats i Recerca del Departament d'Economia Coneixement de la Generalitat de Catalunya. Este trabajo ha sido realizado en el marco del proyecto de investigación titulado "Expresividad, sentimiento y emoción (siglos XII-XV)» (HAR2016-75028-P). Abreviatura utilizada: ACL: Archivo Capitular de Lleida.

1 albert.cassanyes@historia.udl.cat / ORCID iD: http://orcid.org/0000-0002-6046-9201 ingresos del clero durante el Antiguo Régimen, puesto que su posesión implicaba el derecho a recibir un monto fijo en contraprestación al ejercicio de las tareas encomendadas. Por tanto, su detentación fue muy importante y, de hecho, eran muy pocos los eclesiásticos que no ostentaban uno. Además de este carácter económico, los beneficios constituían también la puerta de acceso a la carrera eclesiástica, pues su tenencia era necesaria para la promoción dentro de aquella. ${ }^{2}$

El presente artículo pretende estudiar la concesión de beneficios en la catedral de Lleida durante la década en la que fue obispo el cardenal Antoni Cerdà (1449-1459). Al 
igual que muchos de sus contemporáneos, se trató de un prelado ausente de su diócesis, puesto que ejerció varios oficios en las cortes pontificias de Nicolás $V$ y de Calixto III y en la napolitana del rey Alfonso el Magnánimo. ${ }^{3}$ A pesar de esto, Cerdà se involucró en la gestión de su obispado y, junto a la obtención de algunas gracias por parte de los papas, también participó activamente en la concesión de beneficios y prebendas en la catedral de Lleida. De esta manera, facilitó la promoción de parientes - como su sobrino Gabriel Cerdày familiares. Además, era frecuente que cualquier leridano que fuera a visitarlo en Roma, fuera ese laico o eclesiástico, recibiera una gracia o un beneficio como muestra de estima por parte del cardenal. ${ }^{4}$ Esta circunstancia, y el hecho que el episcopado de Cerdà tuviera lugar en una cronología en que la Iglesia todavía estaba cerrando los convulsos tiempos del Cisma de Occidente y del reciente Concilio de Basilea, justifican la adopción de este obispado como campo de estudio de la dinámica beneficial en la diócesis de Lleida durante el fin de la Baja Edad Media.

La principal fuente utilizada para este ha sido la serie «Actas capitulares» del Arxiu Capitular de Lleida, que se conserva completa para el período estudiado, excepto un vacío de diez meses entre el 1 de marzo de 1456 y el 14 de enero de 1457. Sin embargo, esta laguna se ha podido superar parcialmente gracias a un registro del subsidio papal de Calixto III destinado a la cruzada, impuesto a todo el clero con un beneficio o prebenda superior a las siete libras anuales, y que se recaudó durante los años 1456 y 1457 . Este registro fue publicado por Prim Bertran ${ }^{5}$ y ofrece una fotografía fija de los beneficiados en la catedral de Lleida en el momento del pago del subsidio. A partir de estos fondos, se ha intentado conocer el titular de los beneficios desde el inicio del episcopado de Cerdà, resultando, así, un seguimiento histórico de los detentores de los mismos. Además, estas fuentes han sido completadas por otras series del mismo archivo: en primer lugar, los libros de "Colaciones», en los que se anotaban las distintas provisiones de beneficios o prebendas, pero que presentan algunos saltos temporales, en ocasiones importantes; en segundo lugar, la serie "Procesos apostólicos», que recopila las bulas emitidas desde Roma por el papa, la mayor parte de las cuales se refiere a la concesión de beneficios, tanto de forma efectiva - incluso por sentencias a casos enviados a la curia romana desde Lleida - como haciendo uso de las expectativas.

\section{LOS BENEFICIOS EN LA CATEDRAL DE LLEIDA EN EL SIGLO XV}

Como en las demás iglesias medievales, las capillas de la catedral de Lleida contaban con numerosos beneficios, instituidos por diferentes fundadores a lo largo de su historia. ${ }^{6}$ Muchos de estos fundadores fueron eclesiásticos,

3 La biografía más utilizada sobre Cerdà, a pesar de sus numerosos errores, es Bover de Rosselló 1838: 70-72. Otra biografía basada en fuentes documentales, aunque también matizable, es Strnad 1979: XXIII, 704-706.

4 Lladonosa i Pujol 1976.

5 Bertran i Roigé 1991: 91-103.

6 Una relación de capillas y beneficios de Lleida en Alonso García 1979: 57-88. Sobre la fundación de beneficios en la Edad Media, Borau i Morell 2003: 251-253. generalmente el obispo u otro prebendado catedralicio, aunque la iniciativa podía partir de otro beneficiado. Los laicos tambien podían proceder a la institución de beneficios. De esta manera, los fundadores se garantizaban la celebración de un número determinado de misas, lo que permitiría a sus almas abandonar el Purgatorio en un menor período de tiempo. $^{7}$

Uno de los elementos más importantes en el momento de fundar un beneficio era la definición del patronato, esto es determinar a quién correspondería proveerlo cada vez que quedara vacante. Este asunto no era trivial, puesto que el patrono tenía derecho a presentar sus candidatos para que fueran admitidos por el Cabildo. A través del patronato se podían favorecer parientes o clérigos de confianza, un elemento no exento de importancia en la creación de una red eficaz de contactos y apoyos o en garantizar el sustento a familiares o antiguos servidores. ${ }^{8}$ Al tratarse de un derecho, el patronato podía ser legado, de modo que se hallan beneficios que son provistos por los legítimos herederos de los fundadores. ${ }^{9}$ Sin embargo, en la mayoría de ocasiones, a causa de su condición eclesiástica, los fundadores establecieron como patronos los miembros del Cabildo, de forma individual - el deán o el sacrista, por ejemplo- o en conjunto. Muy frecuentemente este patronato se ejercía junto al obispo mediante un sistema de turnos. Además de con el prelado, el Cabildo también podía compartir el derecho de patronato con otros oficios catedralicios, aunque no siempre necesariamente eclesiásticos. El caso más ilustrativo es el del beneficio de Santa María la Antigua, en cuya provisión participaban el Cabildo y el maestro de obras responsable de la fábrica de la catedral. ${ }^{10}$ Tampoco eran extraños los patronatos ostentados por el Cabildo y personas ajenas a la Iglesia, como puedan ser los beneficios provistos por los canónigos y los herederos del fundador. Un ejemplo se observa en el beneficio de las Once Mil Vírgenes, la provisión del cual correspondía al Cabildo junto a Jordà de Fabra. ${ }^{11}$

En el siglo XV todas las capillas de la sede leridana ya contaban con beneficios en sus altares. Sin embargo, su cuantificación es difícil, puesto que, a lo largo de la centuria, los beneficios se fueron uniendo ${ }^{12}$ y separando por la escasez de rentas que ofrecían ${ }^{13}$, al mismo tiempo que un mismo altar podía hospedar hasta tres beneficios puestos bajo la misma advocación. Prim Bertran cuantificó hasta ciento veintiún beneficios ${ }^{14}$, a los cuales es preciso sumarles veinticuatro más aportados por las fuentes consultadas. Así pues, durante el episcopado de Antoni Cerdà, habría un mínimo de ciento cuarenta y cinco beneficios en la catedral

\footnotetext{
7 Le Goff 1989.

8 Borau i Morell 2003: 253-254; Agúndez San Miguel 2014: 669-670.

9 Barrio Gozalo 2011: 24-26. Los fundadores solían establecer el orden de sucesión, además de indicar la rama colateral que heredaría el derecho en caso de extinción de su línea. Carbonell Boria 1998: 731.

10 ACL, Actas capitulares, AC_0049: ff. 177r-178v.

11 ACL, Actas capitulares, AC_0050: f. 89v.

12 El Cabildo, competente en esta cuestión, esperaba a que se ocasionara una vacante antes de proceder a la unión, de modo que no se documentan desposesiones de beneficiados por este motivo.

13 Las rentas de los beneficios no dependían de las tareas encomendadas, sino de la dotación establecida por el fundador. Bertran i Roigé 1991: 99.

14 Ibídem: 100-102.
} 
de Lleida. ${ }^{15}$ Sin embargo, el número de beneficiados era menor, puesto que algunos clérigos ostentaban dos beneficios simultáneamente. ${ }^{16}$

La fundación de nuevos beneficios en Lleida durante el siglo XV resultaba excepcional. ${ }^{17}$ Bajo el episcopado de Cerdà se documenta solo la creación de dos beneficios. El primero fue instituido en la capilla de San Pedro por el deán Pere Pelegrí, siendo el primer beneficiado su sobrino Bernat Pelegrí, a quien le fue colacionado el 3 de septiembre de 1454. ${ }^{18} \mathrm{El}$ segundo fue fundado en marzo de 1459 por Joan Castanessa, beneficiado de la Expectación del Parto de la Virgen María. Castanessa instituyó un beneficio, puesto bajo la advocación de santo Tomás de Aquino, en la misma capilla donde residía el suyo. Eligió como patronos a sus parientes más cercanos, y dispuso que el beneficio fuera provisto en familiares que llevaran su mismo apellido. ${ }^{19}$

\section{EL ACCESO A LOS BENEFICIOS EN LA CATEDRAL DE LLEIDA}

Ya se ha indicado que la provisión de los beneficios vacantes correspondía a los patronos, fueran estos laicos o eclesiásticos. El procedimiento habitual consistía en la presentación de un candidato al beneficio por parte del patrono correspondiente. A continuación, el Cabildo tenía que aprobarlo. Así pues, a pesar del derecho de patronato, la colación del beneficio incumbía, en último término, al Cabildo, que era el que admitía o rechazaba la propuesta.

Por su parte, el papa también podía conceder beneficios. La decretal Licet ecclesiarum promulgada por Clemente IV en 1265 permitía al pontífice intervenir en el nombramiento de los cargos de las diócesis, en virtud de la plenitud de poderes que poseía, aunque solo se limitaba a los que hubieran fallecido en Roma. En 1316, la constitución Ex debito de Juan XXII incluyó, además, a los beneficios cuyos últimos titulares hubieran sido nombrados por el papa, así como aquellos que hubieran renunciado en su favor o que hubieran sido destituidos. ${ }^{20}$ Desde entonces, los papas fueron aumentando los casos en los que eran aplicables las "reservas pontificias», mediante las cuales adquirieron un protagonismo cada vez mayor en la concesión de beneficios y prebendas mediante bulas y cartas apostólicas. ${ }^{21}$ Dichos documentos, de gracia y de ejecutoria, eran presentados al Cabildo por el procurador del aspirante - se suele indicar el lugar, la fecha y el notario delante del cual se firmó la procuración- y un subejecutor, de forma ordinaria un clérigo del lugar, nombrado por el aspirante o por su

15 Gabriel Alonso contabiliza ciento ochenta y dos localizaciones en la catedral de Lleida, aunque algunas de ellas son desconocidas o posteriores al episcopado de Cerdà. Alonso García 1979: 58-84.

16 No debe confundirse con los beneficios dedicados a dos santos. Borau i Morell 1993: 142-143.

17 En ocasiones, la fundación de beneficios era usada para obtener recursos para la fábrica de la catedral. Por ejemplo, en Barcelona, los que fundaban un nuevo beneficio debían costear una capilla, lo que permitió la construcción de buena parte de las del claustro. Ibídem: 140 La catedral de Lleida, sin embargo, ya estaba prácticamente concluida en el siglo XV, de modo que los nuevos beneficios no se tradujeron en nuevas capillas.

18 ACL, Documentos episcopales, P6A_M3_P2_C04: ff. 38v-39r.

19 Ibídem: ff. 130v-131v.

20 Rapp 1973: 15.

21 Guijarro González 2008: 273. procurador. ${ }^{22}$ El Cabildo tenía que valorar su admisión, lo que frecuentemente sucedía, a causa de la obediencia debida al pontífice. Muchos de los candidatos presentados por el papa residían cerca de él y lo trataban habitualmente, lo que explicaría que este los favoreciera y premiara. Además, permitía obtener apoyos y lealtades, como se puso de manifiesto a lo largo del Cisma de Occidente, período en que las concesiones de beneficios, especialmente bajo la forma de expectativas, se multiplicaron. ${ }^{23}$ Sin embargo, otra práctica común era que los aspirantes a ocupar un beneficio lo solicitaran directamente mediante una instancia o súplica a la curia romana, que contaba con una oficina específica para dicho fin. La concesión de beneficios y prebendas permitía a los papas ingresar importantes montos, puesto que los clérigos que accedían a uno tenían que pagar los denominados "servicios», que podían ser «comunes» - si se trataba de altos cargos elegidos por el papa y los cardenales en consistorio, como un obispado- o «menudos» - cargos que el papa nombraba en solitario-. El pontífice también recibía los «despojos» - bienes poseídos por un cargo difunto proveído por el papa- y las «vacantes» - rendas de los beneficios durante su vacancia- ${ }^{24}$ Así pues, estos nombramientos constituían una de las principales bases de la economía de la Santa Sede, lo que explica que los pontífices proveyeran las prebendas con asiduidad.

Los papas contaban con el procedimiento especial de las expectativas. A través de estas, el pontífice concedía a un clérigo un beneficio sin que este estuviera todavía vacante. Así pues, se remitía al Cabildo la pertinente bula disponiendo que se otorgara al agraciado el primer beneficio que quedara disponible en la catedral. Aunque este método fue muy usado durante el siglo XIV, su utilización parece decrecer hacia la mitad del siglo XV, quizá porque Martín $\checkmark$ prohibió su uso en la provisión de los beneficios mayores de las catedrales o que alguien contara con más de una expectativa, excepto en el caso de zonas en las que los beneficios fueran poco cuantiosos. ${ }^{25}$ Estas medidas, pues, restringieron el uso de las expectativas. Sin embargo, éstas no desaparecieron y, de hecho, su número continuó siendo muy importante a lo largo de la centuria. La acumulación de expectantes esperando una vacante fue frecuente en los cabildos bajomedievales. ${ }^{26}$

Aprovechando el Cisma de Occidente, las monarquías intentaron controlar la concesión de beneficios. ${ }^{27}$ En el marco del Concilio de Constanza, el papa Martín V firmó varios concordatos con los distintos soberanos presentes en él, muchos de los cuales reconocían la participación de los monarcas en la provisión de los beneficios. ${ }^{28}$ En cambio, en Lleida destaca la ausencia de intervención directa real en la provisión de beneficios. Quizá este hecho pueda relacionarse con la falta de una «Iglesia nacional» en los

22 Ibídem: 280.

23 Álvarez Palenzuela 1984: 297-299.

24 Rapp 1973: 12-16.

25 Álvarez Palenzuela 1984: 299, nota 21. Sin embargo, frecuentemente se observa como las bulas apostólicas mencionan dos diócesis unidas mediante la conjunción vel. También la escasa dotación de los beneficios promovió su acumulación en una misma persona. Pérez González 2012: 513-514.

26 Agúndez San Miguel 2014: 671.

27 Rapp 1973: 56-58.

28 Mercati 1919: 144-168. 
reinos hispánicos a causa de la actuación de las monarquías durante el Cisma de Occidente. Es bien sabido que los estados europeos aprovecharon la ocasión que les ofrecía la ruptura de la cristiandad para formar las denominadas «Iglesias nacionales», que tuvieron su paradigma en Inglaterra y Francia. Esto no sucedió en los reinos hispánicos: a pesar de la neutralidad de Pedro IV de Aragón y de la temporal sustracción de obediencia de Enrique III de Castilla, el pretendiente de la obediencia aviñonesa, Benedicto XIII, contó con el apoyo de estos territorios, de modo que no se dieron las condiciones de distanciamiento de la corte papal que habrían permitido el surgimiento de las «lglesias nacionales». Esto no implica que no se tomaran medidas encaminadas a regular la provisión de beneficios; de hecho, abundan las normativas que coartan el acceso de extranjeros a los mismos. ${ }^{29}$ Además, el concordato de 1418 firmado entre Martín V y Juan II de Castilla también limitaba la concesión de beneficios por parte del papa al cumplimiento de las bulas Execrabilis de Juan XXII y Ad regimen ecclesiæ, esta última con una vigencia de únicamente cinco años. ${ }^{30}$ Sin embargo, dicho concordato no fue aplicable a la Corona de Aragón, que sostuvo a Clemente VIII hasta su renuncia en 1429 por los intereses de Alfonso el Magnánimo en Nápoles. En todo caso, los monarcas quisieron favorecer a sus clérigos más afines, incluidos sus confesores o capellanes reales, de modo que solicitaron al papa que les concediera una expectativa. Así pues, se pueden hallar en las bulas referencias a que el nombramiento ha sido propuesto por el rey de Aragón, y que el papa accede en muestra de su amistad. ${ }^{31}$ El único caso explícito de intervención real en Lleida es la concesión de un beneficio el 10 de mayo de 1449 por parte del rey Juan de Navarra a Pedro, presbítero de Zaragoza y capellán real, a quien el monarca confirió beneficios en Lleida y Valencia. ${ }^{32}$

Los obispos también buscaron colocar a sus allegados en los beneficios. Sin embargo, y puesto que los beneficios catedralicios tendían a ser utilizados por los papas, los diocesanos se centraron en las parroquias de su dominio. ${ }^{33}$ Por otro lado, la oligarquía urbana también intentó favorecer a sus miembros, puesto que el acceso a la catedral - sobre todo al cabildo - constituía una herramienta muy eficaz de cara a la creación de redes de contactos que ayudaran a la promoción social de la saga correspondiente. ${ }^{34}$

En general, no había demasiados requisitos para acceder a un beneficio eclesiástico. Junto a la edad canónica y a una

\footnotetext{
29 Rodríguez Llopis y García Díaz 1994: 64-65.

30 Tejada y Ramiro 1862: 9-16.

31 Por ejemplo, Alfonso el Magnánimo intentó favorecer su bibliotecario mayor, el canónigo de Barcelona Joan Torres. ACL, Justicia, P7_ M1_P5_C05: ff. 309r-313r.

32 Beneficios luego confirmados por el papa. Ibídem: ff. 234r-239r.

33 Rodríguez Llopis y García Díaz 1994: 33-39. Aunque el papa también podía intervenir en las parroquias, como hizo Calixto III a favor de Esteve Ribera para la iglesia de San Román de Castre (Ribagorza, diócesis de Lleida) en 1457. ACL, Justicia, P7_M1_P5_C06: sn.

34 Esta cuestión ha sido tratada en diferentes obispados castellanos. Cabe destacar, por su buen estudio, el de Burgos, analizado en Guijarro González 2008: 271-299; y Agúndez San Miguel 2014: 665-687. También es destacable Diago Hernando 2011: 7-39. Por su parte, la relación entre oligarquía y beneficios en la Corona de Aragón medieval no ha sido tratada de forma tan sistemática, aunque cabe destacar algunos trabajos, entre los cuales los de Cristina Borau referente a los beneficios eclesiásticos en Barcelona, materializados en Borau i Morell 2003.
}

formación mínima, solo se exigía formar parte del estado clerical, aunque bastaba la condición de simple tonsurado, esto es el grado inferior, pero suficiente como para disfrutar de los privilegios del clero. ${ }^{35}$ Por este motivo, los beneficios pudieron significar el primer escalón en la carrera eclesiástica de muchas personas. En el caso de Lleida, los estudiantes del Estudio General intentaban obtener un beneficio para financiar sus años universitarios con los que luego promocionar dentro de la Iglesia. Sin embargo, en ocasiones los fundadores podían haber impuesto alguna otra condición específica de acceso, como el cumplimiento de determinadas funciones o la pertinencia a la misma familia del fundador - como estableció Castanessa-; de este modo se garantizaba que las rentas destinadas a estas fundaciones servirían para el sostén de un miembro del mismo linaje. ${ }^{36}$

\section{El turno del patronato eclesiástico catedralicio}

Como se ha indicado, el Cabildo tenía que admitir todos los candidatos presentados por los patronos a los beneficios de la catedral. Sin embargo, el Cabildo de Lleida ejercía la mayoría de veces el patronato de los beneficios. Este podía recaer solo en determinadas dignidades, como el deán, el sacrista - patronos ambos del beneficio de Santa Cecilia- ${ }^{37}$ o el precentor. ${ }^{38}$ Uno de los oficios catedralicios al cual se habían confiado más patronatos era el «capellán de San Pedro». ${ }^{39}$ En otras ocasiones era el Cabildo en su conjunto el que ostentaba el patronato. Los ejemplos son numerosos. Uno de ellos es el beneficio de los Santos Inocentes, que el 1 de febrero de 1457 fue proveído en Llorenç Forner, un antiguo cantor de la catedral ${ }^{40}$, de acuerdo con un privilegio concedido por Nicolás V en $1452 .{ }^{41}$ Otro es el beneficio de Santa María Magdalena, que había sido fundado por Pere Sanahuja en les Borges Blanques, una localidad situada a unos veinticinco quilómetros al sudeste de Lleida, pero que tenía la consideración de prolongación de la ciudad ${ }^{42}$; en 1457 fue provisto a Ramon de Cardona. ${ }^{43}$

Algunos beneficios, por su parte, tenían que ser provistos por el Cabildo y el obispo, siendo frecuente que se optara por una fórmula de turno, de modo que, cada vez que se producía la vacante, correspondería a uno de los dos patronos proveerla. Este fue el caso del beneficio de San Marcial y San Miguel, instituido en la capilla del Palacio Episcopal. Así pues, cuando en 1452 quedó vacante por muerte de Martí Seyol, fue el vicario del obispo quien presentó el aspirante, habida cuenta que el prelado se hallaba ausente. En este caso, la sucesión fue muy tranquila, puesto que el candidato episcopal, el licenciado en Cánones Bernat

35 La mayoría de clérigos medievales no pasaron de la simple tonsura. Pérez González 2012: 498.

36 Rodríguez Llopis y García Díaz 1994: 89.

37 ACL, Actas capitulares, AC_0050: ff. 61v-62r.

38 Ibídem: f. 220r.

39 Como el de San Antonio (ACL, Actas capitulares, AC_0049: f. 175r.), San Saturnino (ACL, Actas capitulares, AC_0050: f. 28v.), San Clemente, mártir (Ibídem: f. 62v.) o San Blas (Ibídem: ff. 145v, 148r y 152v.).

40 ACL, Actas capitulares, AC_0051: f. 18v.

41 ACL, Actas capitulares, AC_0050: f. 50v.

42 Pleyán de Porta 1873: 197.

43 ACL, Actas capitulares, AC_0051: f. 44v. 
Roig, fue admitido el 28 de junio. ${ }^{44}$ Similar fue el caso de la provisión del beneficio de la Cátedra de San Pedro y de Santa Petronila, que también correspondía por turno al prelado y, en su ausencia, a su representante, en este caso el canónigo Antoni Rotlan. ${ }^{45}$ Tampoco hubo problemas en la concesión del beneficio de Jesús a Lluís de Montsuar el 23 de agosto de $1454^{46}$; fue el único candidato al beneficio, restringido a familiares del fundador, el obispo Romeu Sescomes.

Sin embargo, el sistema del turno entre el obispo y el Cabildo no siempre funcionó correctamente, y, en ocasiones, hubo importantes disensiones entre los canónigos y los representantes del prelado. Quizá el caso más destacado fue la provisión del beneficio de las Once Mil Vírgenes. El obispo presentó a Jordi Castelló, pero el canónigo Joan Rabins manifestó que el prelado no tenía derecho a ejercer el patronato, ya que, por turno, correspondía al Cabildo. ${ }^{47}$ Un caso similar tuvo lugar a la hora de proveer la denominada "capilla del Conde», que vacaba por muerte de Bernat Volturina. El patronato correspondía al obispo y al Cabildo por turno, de modo que Cerdà, mediante su procurador -el canónigo Miquel Peris- presentó el candidato Nicolau Vicens, familiar y servidor doméstico del prelado. En el momento de examinar su idoneidad, los canónigos dudaron de si realmente correspondía al obispo el ejercicio del patronato, de modo que se llevó a cabo una votación. El resultado no fue favorable a los intereses episcopales, puesto que el día siguiente el Cabildo presentaba su candidato, Gabriel Roig, y le concedía la capellanía. ${ }^{48} \mathrm{La}$ situación se complicó una semana más tarde, pues el rey Juan II también quiso proponer un aspirante, el presbítero de su capilla Jaume Salvany. A pesar de que sus documentos fueron admitidos ${ }^{49}$, no se conoce la respuesta del Cabildo, aunque seguramente se comunicara al rey que la vacante ya había sido cubierta.

Desacuerdos en los candidatos: disensiones familiares y oposiciones canonicales

Otro tipo de discrepancia muy habitual fue el desacuerdo a la hora de presentar candidatos, no tanto por a quién correspondía, sino por el sujeto que se proponía. Las principales disputas en este sentido se dieron en los beneficios cuyo patronato recaía en varios laicos, puesto que todos tenían que acordar el candidato propuesto a la vacante..$^{50} \mathrm{El}$ caso leridano más ilustrativo es el de los beneficios que habían sido fundados en la capilla de los Requesens, como el de la Natividad de María. El 22 de agosto de 1451 el caballero Lluís de Requesens presentó al Cabildo su candidato, Galceran de Requesens, simple tonsurado. ${ }^{51}$ Esta propuesta contó con la oposición de Joan -caballero- y Caterina Barquer, que el 10 de septiembre siguiente, junto a Bernat de Requesens y a Elionor de Requesens - monja esta del monasterio de Sant Pere de

\footnotetext{
44 ACL, Actas capitulares, AC_0050: f. 85r.

45 Ibídem: f. 219r.

46 Ibídem: f. 187r.

47 Ibídem: f. 223v.

48 ACL, Actas capitulares, AC_0051: ff. 84v-85v.

49 Ibídem: f. 86v.

50 Barrio Gozalo 2011: 23-24.

51 ACL, Actas capitulares, AC_0050: f. 35v.
}

les Puel-les de Barcelona ${ }^{52}$-, presentaron la candidatura de Francesc Cabestany, hijo de Caterina Barquer y de su esposo Joan Cabestany. ${ }^{53}$ El caso terminó en la curia episcopal, que no resolvió en favor de Galceran de Requesens hasta tres años más tarde. Así, el 17 de agosto de 1454, este pudo tomar posesión del beneficio. ${ }^{54}$

Otro caso protagonizado por la misma familia fue el del beneficio de la Aparición del Señor. El patronato correspondía a siete personas: Lluís de Requesens, Galceran de Requesens -que fue lugarteniente de Catalunya-, Francesquina de Requesens, la ya mencionada sor Elionor de Requesens, Elionor Barquera - abadesa del monasterio cisterciense de Santa Maria de Vallsanta (Guimerà)-, y los también sobredichos Caterina Barquer y Joan Barquer. El 9 de abril de 1455 Lluís de Requesens presentó como candidato a Pere de Requesens, simple tonsurado. El día siguiente, Galceran de Requesens propuso otro aspirante, Esteve Ricard, bachiller en Teología. Ante esta primera división, el Cabildo acordó enviar el caso a la curia episcopal. ${ }^{55}$ Por su parte, los otros cinco patronos presentaron conjuntamente un tercer candidato, Joan Cabestany, simple tonsurado e hijo de Caterina Barquer y de Joan Cabestany -que actuó como procurador de estos cinco patronos-. La presentación tuvo lugar el 15 de abril, y los canónigos, igual que habían hecho con la candidatura de Esteve Ricard, lo comunicaron a la curia del obispo. ${ }^{56}$ La mayor discrepancia debía darse entre Lluís y Galceran de Requesens, por una parte, y los otros cinco patronos, por la otra, pues en noviembre de 1457 ambos coincidieron en presentar para la porción canonical fundada por el obispo Guerau de Requesens a Onofre de Requesens, simple tonsurado. Cabe indicar, pero, que Lluís y Galceran de Requesens presentaron por separado la candidatura de Onofre, pues el primero lo hizo el 17 de noviembre ${ }^{57}$, mientras que el segundo esperó hasta el 21 del mismo mes, siendo su procurador el bachiller en Teología Esteve Ricard. ${ }^{58}$

La unión de beneficios también fue la causante de algunos pleitos, especialmente cuando la unión era entre dos beneficios con patronos diferentes. Este fue el caso del litigio acaecido para la provisión del beneficio del Corpus Christi, que había sido unido al de Santa Bárbara. El patrono del primero era Joan Sasala, ciudadano de Lleida, mientras el segundo se hallaba bajo el patronato de Elionor, curadora del mismo en nombre de Miquel Moliner, pupilo del señor de la Granadella. El 22 de agosto de 1457 Sasala presentó a Berenguer Rossell para ostentar el beneficio vacante. ${ }^{59}$ Una semana después, Elionor hizo lo propio con Pere Llaurador. ${ }^{60}$ Como era habitual, el caso fue remitido a la curia episcopal, que no resolvió a favor de Rossell hasta $1459 .{ }^{61}$

52 Zaragoza i Pascual 2004: 66.

53 ACL, Actas capitulares, AC_0050: ff. 38r-39r.

54 Ibídem: f. 186v.

55 Ibídem: f. 209r.

56 Ibídem: f. 210r.

57 ACL, Actas capitulares, AC_0051: f. 42v.

58 Ibídem: f. 44v. A pesar del acuerdo, no fue colacionado hasta el 26 de octubre de 1458. Ibídem: f. 78r.

59 Ibídem: f. 34r.

60 Ibídem: f. 35r.

61 Ibídem: f. 93r. Sin embargo, este caso llegó incluso a Tarragona, sede arzobispal. Sasala y Rossell nombraron procuradores a Guillem Franch, Francesc Laterà y Bartomeu Antoni para que defendieran sus intereses en dicha ciudad. ACL, Justicia, P7_M3_P5_C06, 2/2: f. 1r-v. 
Los patronos eclesiásticos no fueron una excepción, pues en ocasiones se enfrentaron para lograr la elección de sus candidatos. Es el caso de la provisión del beneficio de Santa Cecilia, cuyos patronos eran el deán y el sacrista. El beneficio fue concedido a Marc Barat, candidato propuesto por el deán Manuel de Montsuar el 1 de febrero de $1452 .{ }^{62}$ Sin embargo, no había habido consenso entre los patronos, pues el 7 del mismo mes el sacrista Bernat Bosch presentaba otro candidato, Gabriel Guillem. El Cabildo respondió que la provisión del beneficio había sido realizada "sin contradicción», de modo que rechazó este segundo candidato. ${ }^{63}$ Ya el año anterior el canónigo Bernat Seyfores tuvo que pleitear con Guillem Móra para la provisión del beneficio de San Lázaro: el 13 de octubre de 1451 Seyfores presentó a Antoni Roig64, pero el 4 de noviembre Guillem Móra propuso la candidatura de Arnau Figuera. ${ }^{65}$ Como era habitual, el caso fue llevado a la curia episcopal, que resolvió el litigio dos años después: el 19 de octubre de 1453 Antoni Roig tomó posesión del beneficio. ${ }^{66}$

También se dieron algunos casos - aunque bastante excepcionales - de oposición del Cabildo a un candidato propuesto por los patronos. El más ejemplar en este sentido es el que sucedió en 1451 a la hora de proveer el beneficio de San Juan Bautista y San Juan Evangelista. El patronato del mismo era compartido por cinco personas: Pere Solses, su esposa Joana, Antoni de Garona, Pere d'Oriola y Bernat Destinlella. Los cinco presentaron conjuntamente la candidatura del estudiante Antoni Solses, hijo de Pere y Joana. La propuesta tuvo lugar el 17 de noviembre de 1451, y aquel mismo día el Cabildo se opuso a la misma, lo que implicó que el caso fuera remitido a la curia episcopal. ${ }^{67} \mathrm{En}$ todo caso, Antoni de Garona presentó el 9 de diciembre siguiente otro aspirante, el estudiante Nicolau Olives, que era hijo del apotecario de Lleida Joan Olives, procurador de Garona. A causa del litigio que se había iniciado tres semanas antes, la candidatura de Olives también fue comunicada a la curia para que fuera tenida en consideración. ${ }^{68}$ Sea como sea, en febrero de 1455 Nicolau Olives y su padre se personaron ante el Cabildo con Francesc Major, residente de la diócesis de Vic. Ambas partes mantenían un pleito por el beneficio de San Juan Evangelista. Sin embargo, Major decidió renunciar al litigio -lo que hizo verbalmente ante Pere Teixidor, escribano de la curia episcopal-, de modo que el Cabildo pudo colacionar el beneficio a Nicolau Olives. ${ }^{69}$ Es difícil determinar la relación de este pleito entre Olives y Major y el que mantuvo Olives con Solses y el propio Cabildo leridano. Sin embargo, el resultado fue que Nicolau Olives consiguió hacerse con el deseado beneficio.

En cualquier caso, no hay que considerar que el conflicto fuera inherente al patronato, sino que, en muchas ocasiones, hubo acuerdo amistoso y consenso entre los diferentes miembros que lo ejercían. Por ejemplo, cuando en 1455 Joan Companyó quiso permutar el beneficio que tenía en la iglesia parroquial de San Juan con otro fundado en la catedral, los

\footnotetext{
62 ACL, Actas capitulares, AC_0050: f. 61v.

63 Ibídem: f. 62r.

64 Ibídem: f. 43r.

65 Ibídem: f. 45v.

66 Ibídem: f. 162v.

67 Ibídem: ff. 48v-49r.

68 Ibídem: f. 54v.

69 ACL, Documentos episcopales, P6A_M3_P2_C04: ff. 55v-56v.
}

tres patronos de este último -el prior de la cofradía de Santa María, Pere Mercer; el procurador de los pobres del claustro, Manuel d'Argentona; y el notario Bernat Nogósautorizaron sin problemas conocidos el dicho concambio. ${ }^{70}$

\section{Los beneficios que no vacaban}

La lentitud de las comunicaciones en la Edad Media afectó a la provisión de beneficios, puesto que la presentación de candidatos solo podía realizarse a partir del momento en que aquel quedara vacante por fallecimiento, renuncia o promoción de su titular - excepto en el caso de las expectativas, cuyas bulas podían ser presentadas en cualquier instante-. Por tanto, no era extraño que el Cabildo tuviera que comunicar a algún aspirante que el beneficio que deseaba ya había sido concedido. Uno de los ejemplos leridanos se halla en la porción de los Santos Inocentes, que fue provista al maestro en Artes Antoni Molgosa el 31 de julio de $1450 .{ }^{71}$ A pesar de esto, el 10 de diciembre del mismo año se presentaron las cartas apostólicas sobre su provisión a Lluís Torà. El Cabildo tuvo que informarle que hacía ya cuarenta días que la vacante había sido cubierta y que no era posible desposeer a Molgosa de la prebenda. ${ }^{72}$ A pesar de ello, Torà movió causa ante la curia romana, que, dos años más tarde, emitió una sentencia mediante la cual ordenaba al Cabildo que lo admitiera en la porción. ${ }^{73}$ También presentó pleito Francesc d'Ulzina, estudiante de Cánones, que fue presentado por los paers para el beneficio de Santa María la Antigua el 25 de febrero de 1451. El Cabildo comunicó que el beneficio había sido proveído en noviembre, pero, a pesar de ello, el caso fue remitido a la curia episcopal para que revisara la provisión. ${ }^{74}$ Asimismo, en marzo de 1453 Arnau Manresa fue presentado y admitido en el beneficio de San Juan de la catedral de Lleida. ${ }^{75}$ Tres días más tarde, Bernat Roig, doctor en Cánones, también se postuló para el beneficio y, aunque se le comentó que ya había sido otorgado, sus derechos fueron revisados por la curia del obispo. ${ }^{76}$ Esta resolvió en septiembre de 1455 que Roig tenía derecho al beneficio, de modo que Arnau Manresa fue obligado a resignar en favor de aquel. ${ }^{77}$

No solo las noticias de las vacantes tardaban en llegar, sino también las referentes a determinadas acciones del Cabildo relativas a la gestión de las mismas. El 7 de septiembre de 1450 Francesc Vaquer presentó su candidatura al beneficio de las Once Mil Vírgenes. El Cabildo respondió el día 12 siguiente que este había sido unido a otro beneficio. ${ }^{78} \mathrm{En}$ la misma situación se encontró Bartomeu Granyes - que el 27 de octubre del mismo año solicitó el beneficio de San Antonio, que había sido unido al que ya poseía Arnau Martí doce días antes ${ }^{79}-$, o Francesc Camarasa - que también vio

70 Ibídem: f. 82r-v.

71 ACL, Actas capitulares, AC_0049: f. 150v.

72 Ibídem: ff. 168v-169v.

73 ACL, Justicia, P7_M1_P5_C05: ff. 268v-271r. También ACL, Actas capitulares, AC_0050: f. 109r-v.

74 Ibídem: ff. 6v-7r.

75 Ibídem: f. 135r.

76 Ibídem: f. 135v.

77 Ibídem: f. 220v.

78 ACL, Actas capitulares, AC_0049: ff. 166v-167v.

79 Ibídem: f. 176r. 
como el beneficio de San Tomás mártir al que aspiraba había sido unido al de la Asunción de María hacía poco más de dos semanas.$-^{80}$ Por su parte, el 7 de agosto de 1452 Marc Bonfill solicitó al Cabildo que se le proveyera el beneficio en la capilla de Todos los Santos, que su titular, Berenguer Ferrer, había resignado el 16 de febrero del año anterior. Los canónigos respondieron que el beneficio no vacaba, puesto que Berenguer Ferrer lo había permutado por el de San Onofre, en la iglesia parroquial de San Juan de Lleida; así pues, el beneficio que Bonfill solicitaba había sido concedido a Pasqual Miquel en virtud de la permuta. ${ }^{81}$

\section{LAS PERMUTAS DE BENEFICIOS}

La permuta consistía en el intercambio de beneficios entre los dos clérigos que los ostentaban. Los participantes en el acto debían contar con la autorización del Cabildo -que tenía que reconocer la idoneidad del nuevo beneficiado- y del correspondiente patrono, si era el caso, a quien debía entregarse igualmente un inventario de los bienes del beneficio. ${ }^{82} \mathrm{~A}$ continuación, los dos beneficiados debían resignar sus beneficios ex causa permutationis ante el obispo o, en el caso de ausencia - como en Lleida-, el vicario general.

La práctica de la permuta en Lleida durante el episcopado de Antoni Cerdà fue muy habitual. La mayor parte de estas permutas se dieron entre beneficios de la catedral y de una de las parroquias de la ciudad - se ignora, sin embargo, si el valor de las rentas era igual-.$-^{83}$ La parroquia más frecuente en la documentación es la de San Juan de la Plaza y, sobre todo, los beneficios de San Onofre fundados en dicha iglesia. Pero los beneficios de las otras parroquias también participaron en las permutas, aunque en un nivel muy inferior a los de San Juan. Por ejemplo, Bernat Torroda permutó el beneficio de Santa Marta de la catedral por el de Santa Lucía en la iglesia de San Andrés ${ }^{84}$; Antoni Barratxina, provisto del beneficio de San Antonio, lo permutó por el de San Juan Evangelista en la parroquial de San Martín ${ }^{85}$; Joan Bonamic permutó en 1454 la porción de las Santas Cruces por el beneficio de Santa Laura en la de la Magdalena. ${ }^{86}$ Una mención especial merece el caso de Joan Parellades, que permutó el beneficio de Santa Magdalena que tenía en la catedral por el beneficio de San Salvador instituido en Gardeny que tenía el estudiante Tomás de Lleida. ${ }^{87}$ También era frecuente que se permutaran beneficios catedralicios por otros existentes en el monasterio cisterciense de San Hilario, extramuros de la ciudad. Por su parte, los beneficios fundados en la capilla del Palacio Episcopal fueron objeto de permuta, como hizo Gabriel Calateny. ${ }^{88}$

80 ACL, Actas capitulares, AC_0050: ff. 148r-v y 151r-v. El documento de la unión de los beneficios, que fueron proveídos en Francesc Morelló, en ACL, Documentos episcopales, P6A M3 P2 C04: ff. 7r-9v.

81 ACL, Actas capitulares, AC_0050: ff. 96v-97r. La permuta puede encontrarse en ibídem: ff. $5 \mathrm{v}-6 \mathrm{r}$

82 Borau i Morell 2003: 255

83 Véase Pérez González 2012: 497-523.

84 ACL, Actas capitulares, AC_0051: f. 84r

85 ACL, Documentos episcopales, P6A M3 P2 C04: f. 28r-v. Sobre la iglesia de San Martín, véase Lladonosa i Pujol 1944.

86 ACL, Documentos episcopales, P6A M3 P2 C04: ff. 48r-49r.

87 ACL, Actas capitulares, AC_0049: f. 95r.

88 ACL, Actas capitulares, AC_0050: f. 144r.
Sin embargo, las permutas podían darse con beneficios de cualquier otro lugar. Así pues, son también representativas las permutas de beneficios en iglesias de la diócesis de Lleida, aunque en poblaciones distintas de la ciudad. Por ejemplo, Martí Sartre permutó el beneficio de San Antonio por el de San Salvador que el estudiante Francesc Pelegrí había obtenido en la iglesia de Vilanova de Segrià. ${ }^{89}$ En 1453 Bernat Roig permutó su beneficio en la capilla del Palacio Episcopal con Francesc Vaquer, que le cedió el que tenía en Llardecans. ${ }^{90}$ Otros núcleos de la diócesis que se vieron involucrados en permutas de este tipo fueron Aitona, Benabarre, Zaidín, Montsant, Monzón, Sudanell y Tamarite. Por otro lado, tampoco faltan los ejemplos de permutas de beneficios fundados en diócesis distintas, mayormente catalanas - Seu d'Urgell, Tarragona, Tortosa, Vic-, pero también en otros obispados hispánicos; se trata, básicamente, de permutas de beneficios instituidos en la diócesis de Zaragoza.

En el momento de realizar una permuta, se exigía a los participantes que juraran que no había "pactos ilícitos». Se trataba de una mención a la práctica habitual de utilizar las permutas para conseguir el acceso de un familiar a un beneficio. ${ }^{91} \mathrm{~A}$ pesar del juramento, hubo muchos casos de permutas entre parientes, básicamente a través de la línea de tío-sobrino. Un ejemplo es Pere Terrós, que permutó su porción en la catedral por un beneficio en la parroquia de San Juan que ostentaba su sobrino Manuel Terrós, bachiller en Leyes. ${ }^{92}$ También eran familia Bertran Urgellès y Ferran Urgellès, beneficiados, respectivamente, en las capillas de San Andrés en el Palacio Episcopal y de San Onofre en la iglesia de San Juan, que se intercambiaron en $1452 .{ }^{93}$ Similar fue el caso de Nicolau Castanessa, que en 1459 permutó el beneficio que tenía en la catedral por el de San Vicente en la iglesia de Santa María de Montsant que había conseguido Nicolau Castanessa, simple tonsurado. ${ }^{94}$ En 1458 el doctor en Cánones Bernat Pelegrí permutó un doble beneficio catedralicio con el que tenía otro Bernat Pelegrí en la iglesia de San Juan. Este segundo Bernat Pelegrí era, sin duda, un pariente que iniciaba su carrera eclesiástica, pues contaba con un tutor, su padre Arnau Pelegrí, lo que demuestra que era menor de edad..$^{95}$ La práctica de favorecer el acceso de los nuevos clérigos fue muy habitual, pues en las permutas frecuentemente se menciona la participación de jóvenes menores de veinte o veinticinco años - aunque mayores de dieciséis o dieciocho, respectivamente-, además de muchos estudiantes que, mediante el grado, aspiraban a mejorar su posición en la Iglesia.

En otros casos, este objetivo final no es tan evidente, aunque es posible rastrear la presión ejercida por canónigos $\mathrm{u}$ otros prebendados para conseguir permutas para sus favorecidos. Este podría ser el caso de Manuel de Huesca, beneficiado de San Jaime en la catedral, que permutó su beneficio con Llorenç de Vallterra, un simple tonsurado que tenía el beneficio de San Onofre en la parroquia de San

89 ACL, Actas capitulares, AC 0049: f. 160r-v.

90 ACL, Actas capitulares, AC_0050: ff. 149v-150r.

91 Guijarro González 2008: $27 \overline{7}$.

92 ACL, Actas capitulares, AC_0049: f. 100v.

93 ACL, Actas capitulares, AC_0050: f. 82v.

94 ACL, Actas capitulares, AC_0051: f. 94r.

95 Ibídem: f. 59r. 
Juan ${ }^{96}$, y muy probablemente vinculado al canónigo García de Vallterra. Cabe indicar que Llorenç de Vallterra había obtenido un beneficio en Santa María la Antigua, en la catedral de Lleida, y que lo había permutado el 12 de mayo de 1451 a Tristany Batlle, que lo permutó el día siguiente a Bernat de Setcastella, quizá pariente del canónigo Joan de Setcastella. ${ }^{97}$

Por otro lado, las permutas también podían tener como objetivo final el traslado de los clérigos a otros destinos que fueran de su interés. ${ }^{98}$ Este parece ser el caso de Juan de Tarazona, que ostentaba el beneficio de San Antonio en la catedral de Lleida. En 1453 lo permutó con la porción que Pere Soler había obtenido en la iglesia del Pilar de Zaragoza. ${ }^{99}$ Otro ejemplo sería el de Nicolau Vicens, doméstico y familiar del obispo Cerdà, que ostentaba el beneficio de San Ivo en el monasterio de San Hilario. El 12 de junio de 1451 lo permutó por el beneficio de Jesús que tenía Antoni de Santafé en la catedral. ${ }^{100}$ Seis años más tarde, el 4 de junio de 1457, intercambió este beneficio por el de San Onofre de la parroquia de San Juan que tenía Antoni Peiera. ${ }^{101}$ No es posible discernir los motivos que llevaron a Vicens a permutar su beneficio en dos ocasiones, aunque este hecho - por otro lado, no excepcional- conduce a pensar en el uso -o abuso- de las permutas para alcanzar la realización de los propios fines personales.

\section{PERFIL SOCIOLÓGICO DE LOS PROMOCIONADOS}

Una vez examinadas las formas de acceso a los beneficios eclesiásticos, este apartado pretende aproximarse a tres aspectos fundamentales de los beneficiados que consiguieron hacerse con uno en la catedral de Lleida: sus familias, su origen territorial y su formación académica. Son tres elementos que jugaban un papel decisivo a la hora de aspirar a un beneficio, pues no solo se trataba de cumplir determinados requisitos, sino que también era relevante una compleja dinámica de influencias. El resultado fue que, en muchas ocasiones, no obtenía el beneficio el candidato más idóneo, sino el que se hallaba en mejores condiciones en el momento de solicitarlo.

\section{Parientes y familiares en la provisión de beneficios eclesiásticos}

Las familias fueron un elemento clave para lograr un beneficio. Contar con un prebendado en la catedral -o, incluso, el propio obispo- facilitaba el acceso a un beneficio. Además, no hay que olvidar aquellos que estaban restringidos a parientes del fundador. A pesar de su importancia, las reconstrucciones familiares de la Edad Media son una tarea laboriosa y no exenta de dificultades por la escasez de fuentes. Por otra parte, la documentación fue en ocasiones falsificada para ocultar determinadas relaciones familiares, de modo que un vínculo padre-hijo

\footnotetext{
96 ACL, Documentos episcopales, P6A_M3_P2_C04: ff. 162v-163r.

97 ACL, Actas capitulares, AC_0050: ff. 17r-18r.

98 Agúndez San Miguel 2014: 680.

$99 \mathrm{ACL}$, Actas capitulares, AC_0050: f. 147v.

100 ACL, Actas capitulares, AC_0049: f. 25r-v.

101 ACL, Actas capitulares, AC_0051: f. 28v.
}

en el ámbito eclesiástico podía ser sustituido por el más discreto $-\mathrm{y}$ aceptable- de tío-sobrino. ${ }^{102}$

Las relaciones familiares fueron muy importantes en Lleida, como en toda la cristiandad medieval. Las promociones eclesiásticas no se limitaron a los familiares más o menos directos del obispo - Antoni Cerdà concedió un canonicato a su sobrino-, sino que varios canónigos también hicieron valer sus influencias para conseguir beneficios y prebendas para sus parientes. El caso más destacado fue el de Manuel de Montsuar ${ }^{103}$, que pertenecía a uno de los linajes más importantes de Lleida. ${ }^{104}$ Su familia afianzó su influencia social mediante el control de las instituciones eclesiásticas y civiles. ${ }^{105}$ Manuel de Montsuar fue el principal representante de la saga en el ámbito de la Iglesia: el 31 de marzo de 1432 accedió al beneficio de San Nicolás ${ }^{106}$, que permutó en 1446 a Pere de Santa Eulàlia. ${ }^{107} \mathrm{~A}$ pesar de ello, en 1450 recuperó el beneficio de San Nicolás, en esta ocasión vacante por muerte de Jeroni de Santafé. ${ }^{108}$ Una vez terminados sus estudios, Montsuar inició un ascenso fulminante que lo llevaría a ejercer las mayores responsabilidades en la Iglesia leridana: en agosto de 1450 fue provisto de un canonicato ${ }^{109}$, y designado deán el 9 de septiembre de $1450 .{ }^{110}$ A partir de esta posición privilegiada, favoreció el acceso a beneficios a miembros de su familia. ${ }^{111}$ Por ejemplo, el ya mencionado Lluís de Montsuar obtuvo el beneficio de Jesús, fundado por el obispo Romeu Sescomes. En la provisión del beneficio no se indica ningún parentesco entre el deán Montsuar y el nuevo beneficiado, aunque se destaca el vínculo familiar entre Lluís de Montsuar y el obispo Sescomes, puesto que el beneficio debía ser proveído en un familiar del fundador. El patronato del mismo, pero, era compartido entre el obispo de Lleida - cuyo vicario general era Manuel de Montsuar - y al Cabildo -el deán del cual también era Manuel de Montsuar-. ${ }^{112}$

Otro caso llamativo fue la ya mencionada provisión del beneficio de las Once Mil Vírgenes. El obispo Cerdà, mediante su procurador Antoni Rotlan, presentó su candidato, Jordi Castelló, clérigo simple tonsurado. Sin embargo, el canónigo Joan Rabins arguyó que correspondía

102 Rodríguez Llopis y García Díaz 1994: 16-17.

103 La bibliografía sobre este personaje es muy abundante y este no es el lugar para exponerla de forma exhaustiva. Véase la clásica obra Lladonosa i Pujol 1962. Una de las aportaciones más recientes es Busqueta Riu 2011.

104 Cossé y Lladonosa i Pujol 1982. También Busqueta Riu 2011: 17-31.

105 Conejo da Pena 2009: 329-330. Sobre todo la Paeria, principal órgano municipal, en el marco del fenómeno medieval de control de este por parte de la oligarquía. Busqueta Riu 2000: 81-82.

106 ACL, Colaciones, CL_0002: f. 72r.

107 ACL, Colaciones, CL_0009: f. 2r-v.

108 ACL, Actas capitulares, AC_0049: f. 142v. Santafé había conseguido el beneficio tras la resignación de Pere de Santa Eulàlia en 1447. Ibídem: f. 10r-v.

109 La presentación de las bulas papales en ibídem: f. 156r. La resolución en ibídem: ff. 156v-157r.

110 Ibídem: ff. 167v-168v.

111 Aunque también se preocupó de aumentar sus rentas. El 17 de marzo de 1453 el Cabildo unió al deanato los frutos que se obtenían por el beneficio de San Antonio de Viana. ACL, Actas capitulares, AC_0050: f. 134r. Este beneficio había sido fundado por el arcediano Guillem de Bellvís y vacaba por muerte de Bernat Ciprés, que lo había obtenido por permuta el 14 de octubre de 1394. ACL, Colaciones, CL_0001: f. 41r-v.

112 ACL, Actas capitulares, AC_0050: ff. 184v y $187 \bar{r}$. 
al Cabildo proveer aquel beneficio, de acuerdo con el sistema de turnos, por lo que propuso que se concediera a su sobrino, el estudiante Joan Rabins. A esta pretensión se opuso el canónigo Francesc Miquel, que sugirió que el beneficio fuera concedido a su hermano Pere Miquel. ${ }^{113}$ En otras palabras, los canónigos procuraron favorecer sus familiares, haciendo uso de su influencia y maniobrando en el interior del Cabildo. Sin embargo, también hay que valorar la afinidad entre los capitulares, ya que las relaciones entre Joan Rabins y Francesc Miquel no pasaban por su mejor momento; de hecho, cinco días después de la presentación de sus candidatos, Rabins y Miquel firmaban una concordia. ${ }^{114}$ Por su parte, el beneficio fue concedido al estudiante Joan Rabins. En cualquier caso, el 7 de diciembre de 1457, y por orden procedente de Tarragona - capital de la archidiócesis a la cual pertenecía Lleida-, la curia episcopal y el Cabildo anularon la colación de dicho beneficio. ${ }^{115}$

\section{Los orígenes geográficos de los aspirantes a los beneficios}

La determinación de los orígenes de los beneficiados de la catedral de Lleida es una tarea supeditada, en gran medida, a un estudio biográfico de cada uno de ellos, lo que sobrepasa el objetivo del presente trabajo. Sin embargo, en ocasiones las actas de las provisiones mencionan la procedencia de los aspirantes. Esto sucedía porque era habitual que se tomaran medidas para favorecer el acceso de los naturales del lugar a los beneficios, tanto para promocionar a los propios habitantes como para evitar la salida de las rentas del territorio. ${ }^{116}$

Muchos de los candidatos a un beneficiado en la catedral leridana eran catalanes o procedían de las distintas diócesis de Catalunya. De Barcelona venían Joan Comes y Joan Pla. ${ }^{117}$ También era clérigo de la diócesis barcelonesa - sin que esto implique que fuera originario de la mismaMarc Barat. ${ }^{118}$ Más escasos fueron los clérigos gerundenses: en 1456 Miquel Val, canónigo de Girona, se presentó sin éxito para una vacante en Lleida. ${ }^{119}$ De la más cercana diócesis de Urgell procedía Francesc Florensa, que aspiró al beneficio de las Once Mil Vírgenes en $1452 .{ }^{120} \mathrm{El}$ único caso documentado de un clérigo procedente de Tortosa - aunque no necesariamente natural de esta diócesis - es el de Antoni Perpinyà, que obtuvo un canonicato en $1457 .{ }^{121}$ En todo caso, la mayoría de beneficiados procedía de la diócesis de Lleida y, seguramente, de la misma ciudad. Sería

113 Ibídem: f. 223v. El patronato del beneficio también recaía en Jordà de Sebra, puesto que esta prebenda era el resultado de la unión de dos beneficios fundados en la capilla de las Once Mil Vírgenes: el del obispo y Cabildo y el de Jordà de Sebra. ACL, Documentos episcopales, P6A_M3_P2_C04: ff. 91v-92v. Sebra presentó como candidato a Joan Desvalls, hijo del ciudadano Bertran Desvalls. Ibídem: f. 83r-v.

114 ACL, Actas capitulares, AC 0050: f. 223v.

115 ACL, Actas capitulares, AC_0051: f. 47r. Aunque Rabins había permutado este beneficio por el de San Onofre que tenía Pere Ballester el 20 de febrero de 1456. ACL, Documentos episcopales, P6A_M3_P2 C04: f. 89r-v.

116 Canellas 1954: 44.

117 ACL, Actas capitulares, AC_0050: ff. 33v y 179v, respectivamente.

118 Ibídem: f. 61v.

119 Ibídem: f. 228r.

120 Ibídem: f. 90v.

121 Ibídem: f. 27v. el caso de Galceran de Requesens, que obtuvo el beneficio de Santa María en la capilla de los Requesens de la catedral ${ }^{122}$, o de Onofre de Requesens ${ }^{123}$, ambos pertenecientes a uno de los linajes más notables de la ciudad. También Miquel Soler, que aspiraba al beneficio de los Santos Inocentes, era leridano. ${ }^{124}$ Asimismo, hubo otros clérigos procedentes de la diócesis de Lleida, aunque de los territorios del Reino de Aragón. Este fue el caso de Pedro Muñoz, natural del lugar de Volturina ${ }^{125}$, de Cristòfol Benet, que ya tenía un beneficio en la iglesia de San Benito de Tamarite ${ }^{126}$, o de Marc Bonfill, que era rector de Albalate, aunque residía en Roma. ${ }^{127}$

A pesar de la importancia de los vínculos familiares y de la preponderancia de los catalanes, hubo también varios clérigos forasteros que consiguieron un beneficio en la sede leridana. En la mayoría de casos, procedían de las diócesis del Reino de Aragón, principalmente de Zaragoza, un territorio con el cual Lleida tenía una especial relación. Por ejemplo, de la ciudad de Zaragoza venía Francesc Vaquer. ${ }^{128}$ De la misma diócesis procedían también Nicolau Marti ${ }^{129}$ y Manuel de Huesca, originario este último de Alcañiz. ${ }^{130}$ La diócesis de Tarazona también proporcionó algunos beneficiados, aunque en un número inferior a Zaragoza. Por su parte, el Reino de Valencia tuvo también una estrecha relación con Lleida. Los leridanos habían sido uno de los principales activos en la conquista de Valencia y en su posterior repoblación. ${ }^{131}$ Además, el Estudio General atrajo muchos valencianos, que conformaron una comunidad muy destacada. ${ }^{132}$ No sería extraño que algunos de estos estudiantes, aprovechando los años de estancia en la ciudad, ya buscaran -o incluso obtuvieran - beneficios eclesiásticos. Por ejemplo, Joan Pedró era clérigo de Valencia cuando se presentó al beneficio de San Vicente en $1452 .{ }^{133}$ Finalmente, no se conocen beneficiados procedentes del Reino de Mallorca, a pesar del origen mallorquín del obispo de Lleida, el cardenal Antoni Cerdà.

\section{La formación académica de los beneficiados}

Una de las principales preocupaciones de la Iglesia medieval fue la formación del clero. Los eclesiásticos tenían que ser personas instruidas, que conocieran la lengua latina y que poseyeran grados universitarios. Este afán no era novedoso del siglo XV, sino que ya en la centuria precedente se concedían beneficios a clérigos destacándose como principal mérito el haber obtenido un grado. También la escasa formación del clero fue uno de los aspectos que el

\footnotetext{
122 Ibídem: f. 35v. Esta era la capilla de la Epifanía, construida por el obispo Guerau de Requesens.

123 ACL, Actas capitulares, AC_0051: f. 42v.

124 Ibídem: f. 18r.

125 ACL, Actas capitulares, AC_0049: f. 171r-v. Actualmente, Volturina es un núcleo deshabitado que pertenece al municipio de Secastilla y a la diócesis de Barbastro, creada en 1573.

126 ACL, Actas capitulares, AC_0051: f. 100r.

127 ACL, Actas capitulares, AC_0050: f. 96v.

128 ACL, Actas capitulares, AC 0049: f. 114r.

129 ACL, Actas capitulares, AC_0050: f. 219r.

130 ACL, Actas capitulares, AC_0049: f. 146v.

131 Guinot Rodríguez 1999.

132 Gayà Massot 1950; Cruselles Gómez 1992: 149-150.

133 ACL, Actas capitulares, AC_0050: f. 91v. Sobre los beneficios valencianos, véase Carbonell Boria 1998: 729-756.
} 
Concilio de Constanza propuso reformar en el momento de la elección de Martín V, que, de hecho, dispuso que los obispos y las dignidades catedralicias poseyeran un título universitario, y que los graduados contaran con preferencia en la obtención de beneficios. ${ }^{134}$

En la diócesis de Lleida abundaron los beneficiados que tenían un título universitario, aunque las fuentes documentales no siempre mencionan los estudios que pudieran haber cursado. No hay que olvidar que la ciudad contaba con un estudio general fundado en 1300 por el rey Jaime II de Aragón, en el cual podían cursarse los grados de Artes y Filosofía, de Medicina y de Derecho, tanto en su rama de Leyes como en la de Cánones. Por su parte, los estudios de Teología no se implantaron en la institución hasta 1430, a pesar de la existencia de la denominada "cátedra del alba», que era leída por los franciscanos en la iglesia parroquial de San Juan ${ }^{135}$, y de las enseñanzas que se impartían los conventos de las órdenes mendicantes.

El título universitario más habitual que tenían los beneficiados de la catedral de Lleida era el de Derecho Canónico, en cualquiera de sus grados: bachiller, licenciado -más extraño, al tratarse de un trámite-, o doctor. No parece que contar con uno u otro grado resultara fundamental para tener más o menos opciones de acceder a una prebenda; de hecho, Ramon Rossell era solo bachiller en Cánones en el momento en que obtuvo su canonicato en $1450 .{ }^{136}$ Los que optaron por el Derecho Civil también pudieron acceder a los beneficios; Manuel de Montsuar aparece referido como doctor en Leyes en el momento en que se postula para el beneficio de San Nicolás. ${ }^{137}$ Menos numerosos, aunque no desdeñables, fueron los graduados en Teología, como el bachiller Francesc Vaquer. ${ }^{138}$ Un último colectivo por lo que se refiere a formación eran los graduados en Artes y Filosofía. Estos estudios se consideraban básicos, de modo que eran exigidos para acceder a los "grados mayores» - Medicina, Derecho y Teología-. Por este motivo, hay que suponer que todos los que acreditaban uno de estos tres grados ya habían superado los cursos del "grado menor». A pesar de que eran muy pocos los que se conformaban con haber obtenido un título en Artes y Filosofía, en ocasiones aparece documentado algún beneficiado que solo alega este mérito, sin menoscabo de que luego pudiera ampliar su formación con otros estudios. Fue el caso de Antoni Molgosa, maestro en Artes, a quien se concedió una porción canonical en $1450 .{ }^{139}$

Otro grupo aparte lo representan aquellos clérigos que accedieron al beneficio cuando todavía cursaban estudios. No se trata de un fenómeno extraño: era habitual que los eclesiásticos estudiantes se procurasen un beneficio que les permitiera obtener las rentas necesarias para su sustento durante los años universitarios. Aunque los ingresos fueran escasos, el disfrute de un beneficio les permitía dedicarse únicamente a los estudios para, una vez graduados, aspirar a una prebenda mayor. Además, el acceso a un beneficio

134 Álvarez Palenzuela 1984: 297-300.

135 Era una lectura gratuita y abierta, leída en catalán, de modo que cualquier persona podía acudir.

136 ACL, Actas capitulares, AC_0049: ff. 145v-146r.

137 Ibídem: f. 142v.

138 Ibídem: f. 114r.

139 Ibídem: f. 150v. también suponía empezar la carrera eclesiástica. Este fue el caso de Manuel de Huesca o del ya citado Joan Rabins ${ }^{140}$, para indicar algunos.

\section{CONCLUSIONES}

El presente artículo ha querido estudiar el acceso de los eclesiásticos a los beneficios fundados en la catedral de Lleida. El período abarcado es de solo diez años, pero permite observar una casuística y una complejidad de casos que evidencian la dinámica bajomedieval de la concesión de beneficios en la diócesis leridana, extrapolable a las otras - todavía escasamente estudiadas - sedes de la Corona de Aragón. Además, también se pueden extraer algunas consideraciones conclusivas a partir de los datos que se han ido aportando.

En primer lugar, hay que destacar que las conexiones entre los clérigos y las principales familias de Lleida fueron muy numerosas. Las sagas más importantes a inicios del siglo XV eran los linajes Botella, Romeu, Gralla, Santcliment, Colom, Olzinelles, Espens, Montsuar, Carcassona, Desbosc -o Bosch-, Pou, Navarra y Calbet. ${ }^{141}$ Algunos de estos apellidos aparecen en los beneficios. Por ejemplo, los Botella estaban representados por el canónigo Montserrat Botella o el porcionero Francesc Botella, mientras los Romeu, los Santcliment o los Colom habían fundado capillas e instituido beneficios, de modo que ostentaban el patronato de buena parte de estos, como el beneficio de Santo Domingo, cuyo patrono era Joan de Santcliment. Sin embargo, el caso más destacado es el de los Montsuar y el del deán Manuel de Montsuar. Se dio, por tanto, una aristocratización del clero catedralicio, a la par que una política nepotista encaminada a favorecer los parientes y otros colaboradores del obispo Cerdà y los canónigos de Lleida o a los miembros de las familias más notables de la ciudad.

Otro hecho a destacar es la cierta variedad en el origen territorial de los aspirantes a los beneficios. Muchos de ellos procedían de las diócesis de Catalunya, aunque la mayor parte de los postulantes ya se encontraba en el obispado de Lleida antes de promover su candidatura. Tampoco hay que menospreciar la cierta importancia de los candidatos procedentes del obispado de Barcelona, que fue el que más aspirantes aportó, sin contar la diócesis leridana. Muy destacables son los vínculos de Lleida con Valencia, que no deberían separarse de la importancia que los valencianos fueron tomando en el Estudio General de Lleida, lo que se materializó en la creación de la nación valenciana en 1419. En cualquier caso, se observa un interés en que la provisión de los beneficios vacantes se realizara a partir del clero de la misma archidiócesis de Tarragona, que, a mediados del siglo XV - y hasta las reformas de 1470 y 1492-, aglutinaba las diócesis catalanas y valencianas.

Igualmente notoria fue la presencia de aragoneses. La diócesis leridana incorporaba a su seno las parroquias de la Franja de Aragón, que retuvo hasta el siglo XX. Por tanto, abundaron los aragoneses que formaban parte de la misma

140 Ibídem: f. 146v y ACL, Actas capitulares, AC_0050: f. 223v, respectivamente.

141 Ferrer Mallol 1992: 293-314. Algunos más son mencionados en Conejo da Pena 2009: 329-330. 
comunidad diocesana de Lleida, además de clérigos que procedían de los obispados de Zaragoza y Tarazona. No es un caso extraño, básicamente porque las relaciones entre la ciudad del Segre y el Reino de Aragón eran constantes, sobre todo por el hecho que Lleida era un lugar de paso obligado que comunicaba el reino aragonés con la costa mediterránea y los principales centros políticos y económicos de la Corona de Aragón a mediados del cuatrocientos, entre ellos la corte real establecida en Nápoles.

Los beneficios eclesiásticos eran anhelados por buena parte del clero, puesto que eran fundamentales para promocionar luego en la jerarquía eclesiástica. ${ }^{142}$ Muchos jóvenes tonsurados que iniciaban la carrera lo hicieron a través de la obtención de un beneficio, bien por provisión directa, bien mediante el método de la permuta. En cualquier caso, y en parte vinculado a la aristocratización del clero, había un interés por parte de los prebendados en favorecer a sus allegados ${ }^{143}$, de modo que la provisión de beneficios podía llegar a ser extremadamente complicada. Se observa una mayor facilidad en dicha provisión cuando el patronato es ejercido por el Cabildo en su conjunto, pues no se hallan disputas de ningún tipo. Este hecho ya no se constata en los casos en que el Cabildo compartía el patronato con el obispo. A pesar de la existencia del sistema de turnos, el mal funcionamiento del mismo dio lugar a frecuentes desavenencias entre las partes. Por otro lado, el patronato laico no supuso tampoco una provisión tranquila, pues los aspirantes no solo debían contar con la aprobación de los distintos patronos - a veces cada patrono presentaba un pretendiente propio-, sino también del Cabildo.

Buena parte de estos conflictos desembocaban en un litigio en la curia episcopal, que se erigió como el organismo judicial competente en esta materia. De hecho, la práctica habitual del Cabildo cuando se presentaba más de una candidatura a un mismo beneficio consistió en trasladar el caso a los oficiales del obispo. De forma resumida, el proceso se basaba en determinar quién tenía más derecho a ocupar la vacante. Este mismo procedimiento se aplicaba en el caso de los beneficios en expectativa. ${ }^{144}$ La resolución definitiva de estos casos no llegaba hasta transcurrido un mínimo de dos años desde el inicio del litigio, por lo que algunos beneficios quedaron vacantes durante el pleito. En ocasiones, el conflicto podía terminar por resolverse en la curia romana tras una cadena de apelaciones. ${ }^{145}$

A diferencia de la provisión de beneficios, las permutas no contaron con similares dificultades a la hora de llevarse a cabo, seguramente por la necesidad de una autorización capitular previa a su materialización. Sin embargo, hay que destacar el importante número de beneficios que fueron objeto de intercambio durante los diez años de episcopado de Antoni Cerdà: un total de sesenta y seis permutas documentadas; para un período de cincuenta años (13911440), Guijarro documenta solo treinta en el obispado de Burgos $^{146}$, mientras Agúndez menciona veinte en catorce

142 En Barcelona, el perfil habitual del beneficiado era el de un joven eclesiástico que acababa de terminar sus estudios. Borau i Morell 2003: 253.

143 Diago Hernando 2011: 15-17.

144 García y García 2002: 67-68.

145 Barrio Gozalo 2011: 25-26.

146 Guijarro González 2008: 276-277. años (1456-1470) en la misma diócesis. ${ }^{147}$ Por ahora no es posible determinar a qué se pudo deber este fenómeno recurrente de las permutas en Lleida, aunque quizá se deba buscar una parte de la explicación en el hecho de que la ciudad contaba con el Estudio General y que, por tanto, la movilidad de clérigos que se trasladaban a ella para cursar estudios universitarios implicara un mayor dinamismo en la concesión de beneficios. Sin embargo, resulta extraña la nula presencia de permutas en las que participen beneficios valencianos, sobre todo si se tienen en cuenta las relaciones entre Lleida y Valencia.

Los beneficiados continuaron sucediéndose a lo largo de los siglos al frente de los distintos beneficios de Lleida. Su nómina permite observar cómo parientes y colaboradores de los linajes más importantes y de los detentores del poder fueron controlando el clero catedralicio, en una práctica que buscaba tanto prestigio social y poder político y eclesiástico como premiar la fidelidad y los servicios. A tal efecto, el artículo ha pretendido arrojar un poco de luz en el conocimiento de los beneficiados de mediados del siglo XV. La Guerra de Sucesión y la conversión de la catedral de Lleida en cuartel en 1707 implicó el traslado del culto y, por tanto, de los beneficios, a nuevos recintos - la iglesia de San Lorenzo y, después, la nueva catedral dieciochesca-, perdiéndose, de esta forma, la nomenclatura medieval. Las desamortizaciones del siglo XIX acabaron por finiquitar la centenaria institución beneficial. 
ANEXO: BENEFICIADOS EN LA CATEDRAL DE LLEIDA DURANTE EL EPISCOPADO DE ANTONI CERDÀ (1449-1459) $)^{148}$

\begin{tabular}{|c|c|}
\hline Anunciación de María & $\begin{array}{l}\text { Pau Bonafé (...-1448) } \\
\text { Joan Cervera (o Serrava) (1450-...) }\end{array}$ \\
\hline Anunciación de María (PB) & Pere Viladomat \\
\hline Aparición del Señor $(*)$ & Guillem Ricard (...-1455) \\
\hline Ascensión del Señor & $\begin{array}{l}\text { Antoni Miquel (...-1456) } \\
\text { Maties Espill }(1456-\ldots) \\
\end{array}$ \\
\hline Asunción de María & $\begin{array}{l}\text { Bernat Volturina }(. .-1454) \\
\text { Joan Agramunt }(1454-1459) \\
\text { Arnau de la Borda (1459-...) }\end{array}$ \\
\hline Asunción de María & \begin{tabular}{|l} 
Pere de Valldepérez (...-1450) \\
Guillem de la Móra (1450-1452) \\
Bernat Berenguer (1452-1454) \\
Joan Berenguer (1454-1455) \\
Arnau Manresa (1455-...) \\
\end{tabular} \\
\hline Asunción de María & Francesc Morelló \\
\hline Asunción de María (PB) & Joan Cervera \\
\hline $\begin{array}{l}\text { Cátedra de San Pedro y Santa } \\
\text { Petronila }\end{array}$ & \begin{tabular}{|l|}
$\begin{array}{l}\text { Antoni Espert (1422-1455) } \\
\text { Jordi Castelló (1455-...) }\end{array}$ \\
\end{tabular} \\
\hline Conversión de San Pablo (PB) & Arnau Borrell \\
\hline Conversión de San Pablo (PB) & Pere Morell \\
\hline $\begin{array}{l}\text { Conversión de San Pablo, } \\
\text { ermitaño }\end{array}$ & $\begin{array}{l}\text { Antoni Capdevila (...-1458) } \\
\text { Pere Serra (1458-...) } \\
\end{array}$ \\
\hline Corpus Christi & \begin{tabular}{|l|} 
Miquel Sagrera (1447-1457) \\
Berenguer Rossell (1457-...) \\
\end{tabular} \\
\hline Epifanía (PB) & Guillem Ricard \\
\hline Esperanza (PB) & Antoni Garoça \\
\hline Expectación del Parto de María & \begin{tabular}{|l} 
Pere Vila (...-1454) \\
Joan Albert (1454-1455) \\
Bartomeu Ponts (1455-...) \\
\end{tabular} \\
\hline Expectación del Parto de María & \begin{tabular}{|l|} 
Joan Sastre $(. . .-1457)$ \\
Joan Castanessa (1459) \\
Nicolau Castanessa (1459-...) \\
\end{tabular} \\
\hline Invención de San Esteban $(*)$ & Pere Morell (...-1461) \\
\hline Invención de San Miguel (PB) & Joan de Peralta \\
\hline Jesús & $\begin{array}{l}\text { Joan Beralda (...-1454) } \\
\text { Lluís de Montsuar (1454) } \\
\text { Marc Berard (1454-...) } \\
\end{array}$ \\
\hline Jesús & \begin{tabular}{|l} 
Ponç de Villalonga (...-1449) \\
Antoni Ponç de Villalonga (1449-...) \\
\end{tabular} \\
\hline Jesús (PB) & Pere Cervera \\
\hline Jesús & $\begin{array}{l}\text { Llorenç Vallero (...-1447) } \\
\text { Antoni de Santafé (1447-1451) } \\
\text { Nicolau Vicens (1451-1457) } \\
\text { Antoni Perera (1457-...) } \\
\end{array}$ \\
\hline Natividad de María & $\begin{array}{l}\text { Llorenç d'Alcoretge (...-1451) } \\
\text { Vacante por litigio (1451-1454) } \\
\text { Galceran de Requesens (1454-1457) } \\
\text { Martí Joan Agulló (1457-...) }\end{array}$ \\
\hline Natividad de María (*) & $\begin{array}{l}\text { Pere Trebay }(\ldots-1458) \\
\text { Pere Roig }(1458-\ldots)\end{array}$ \\
\hline Octava de San Juan $(*)$ & $\begin{array}{l}\text { Lluís Marçal (...-1453) } \\
\text { Arnau Manresa (1453-...) }\end{array}$ \\
\hline
\end{tabular}

148 Se han marcado con asterisco $\left({ }^{*}\right)$ los beneficios que solo se han localizado en las fuentes documentales consultadas. Por otro lado, los beneficios mencionados en el artículo de Prim Bertran se refieren con las iniciales (PB). Los beneficios sin indicación son aquellos que se constatan tanto en las fuentes consultadas como en el registro estudiado por Bertran. Sin duda, algunas de las omisiones puede deberse a la no constatación documental de la sucesión en un beneficio.

\begin{tabular}{|c|c|}
\hline Once Mil Vírgenes & $\begin{array}{l}\text { Pere Ramon Bertran (...-1450) } \\
\text { Jaume Gumbert (1450-1452) } \\
\text { Pere Beralda (1452-1454) } \\
\text { Joan Bonamic (1454-1455) } \\
\text { Joan Rabins (1455-1456) } \\
\text { Pere Ballester (1456-...) }\end{array}$ \\
\hline Pasión de la Imagen de Cristo & \begin{tabular}{|l|} 
Joan Castanessa $(. . .-1459)$ \\
Joan Costa $(1459-. .)$. \\
\end{tabular} \\
\hline Purificación de María & $\begin{array}{l}\text { Pere Eiximenis (...-1449) } \\
\text { Bartomeu Blasco (1449-1457) } \\
\text { Joan d'Albesa (1457-...) }\end{array}$ \\
\hline Purificación de María (PB) & Aparici Tolosa \\
\hline Purificación de María (PB) & Aparici Tolosa \\
\hline San Agustín & $\begin{array}{l}\text { Bernat Matas (1446-1449) } \\
\text { Lluís Passamant (1449-1454) } \\
\text { Antoni Cabanyes (1454) } \\
\end{array}$ \\
\hline $\begin{array}{l}\text { San Andrés en el Palacio } \\
\text { Episcopal }\end{array}$ & $\begin{array}{l}\text { Bernat Urgellès (...-1452) } \\
\text { Ferran Urgellès (1452-1455) } \\
\text { Bernat Aguilar (1455-...) }\end{array}$ \\
\hline San Antonio & $\begin{array}{l}\text { Martí Sastre (...-1450) } \\
\text { Francesc Pelegrí (1450-...) }\end{array}$ \\
\hline San Antonio (*) & \begin{tabular}{|l|} 
Francesc Exulbe (...-1450) \\
Arnau Martí (1450-...) \\
\end{tabular} \\
\hline San Antonio & \begin{tabular}{|l|} 
Francesc Cabestany (...-1451) \\
Domènec Pere (1451-1452) \\
Juan de Tarazona (1452-1453) \\
Pere Soler (1453-1455) \\
Antoni Lentes (1455-...) \\
\end{tabular} \\
\hline San Antonio & Gabriel Torres (1446-...) \\
\hline San Antonio & Simó Sió (...-1461) \\
\hline San Antonio (PB) & Antoni Cavero \\
\hline San Antonio (PB) & Miquel Sagrera \\
\hline San Antonio & $\begin{array}{l}\text { Antoni de Barratxina (1447-1454) } \\
\text { Guillem Badia (1454-1459) } \\
\text { Gaspar Sunyer (1459-...) } \\
\end{array}$ \\
\hline San Antonio & \begin{tabular}{|l|} 
Bernat Ciprés (...-1453) \\
Manuel de Montsuar (1453-...) \\
\end{tabular} \\
\hline San Antonio & \begin{tabular}{|l} 
Francesc Cabestany $(. . .-1451)$ \\
Jaume Salvany $(1451-\ldots)$
\end{tabular} \\
\hline San Bartolomé & Joan Ferrer (1448-...) \\
\hline San Bartolomé & Domènec Solanell (...-1464) \\
\hline San Benito y San Ponce & $\begin{array}{l}\text { Bernat Salvador (...-1459) } \\
\text { Antoni Vedilla (1459-...) } \\
\end{array}$ \\
\hline San Bernardo & \begin{tabular}{|l} 
Pere Bartoli (...-1451) \\
Pere Barrufo (1451-...) \\
Mateu Montgay (?) \\
\end{tabular} \\
\hline San Bernardo & Mateu Montgay (1448-...) \\
\hline San Bernardo & $\begin{array}{l}\text { Antoni Gui (...-1454) } \\
\text { Mateu Montgay (1454-...) (unido al } \\
\text { anterior) }\end{array}$ \\
\hline San Blas $(*)$ & $\begin{array}{l}\text { Bernat del Camp (...-1453) } \\
\text { Pere Ballester (1453-...) }\end{array}$ \\
\hline San Clemente, papa $(*)$ & 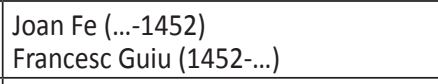 \\
\hline San Esteban & Jaume Arnau (1448-1461) \\
\hline San Esteban & $\begin{array}{l}\text { Montserrat Gras (...-1453) } \\
\text { Pere Sabatés (1453-...) } \\
\end{array}$ \\
\hline San Fabián y San Sebastián $\left({ }^{*}\right)$ & Antoni Salvador (1452-...) \\
\hline San Felipe (PB) & Gabriel de Tàrrega \\
\hline San Francisco & $\begin{array}{l}\text { Pere de Malacanuda }(. . .-1450) \\
\text { Antoni Salvador }(1450-\ldots)\end{array}$ \\
\hline San Francisco y Santa Catalina & $\begin{array}{l}\text { Gabriel Cogoll (...-1454) } \\
\text { Bernat Carnicer (1454-...) (unido al } \\
\text { beneficio de San Marcos) }\end{array}$ \\
\hline
\end{tabular}




\begin{tabular}{|c|c|c|c|}
\hline \multirow[t]{2}{*}{ San Gil } & \multirow{2}{*}{\begin{tabular}{|l|} 
Simó del Corn $(\ldots-1449)$ \\
Antoni Soler $(1449-\ldots)$ \\
\end{tabular}} & San Pedro $(*)$ & Francesc Sogues (1454?-...) \\
\hline & & San Pedro $(*)$ & Pere Florensa (1454?-...) \\
\hline San Gregorio $(*)$ & \multirow{2}{*}{$\begin{array}{l}\text { Joan Armengol (...-1454) } \\
\text { Joan Serra (1454-1457) } \\
\text { Sancho Darrada (1457-...) } \\
\end{array}$} & San Pedro, mártir & \begin{tabular}{|l} 
Ramon Pasqual (...-1451) \\
Pere Amorós (1451-...)
\end{tabular} \\
\hline \multirow[t]{2}{*}{ San Jaime $(*)$} & & San Salvador & \begin{tabular}{|l|} 
Bartomeu Blasco (...-1449) \\
Joan Berenguer (1449-1460)
\end{tabular} \\
\hline & $\begin{array}{l}\text { Penafreita (...-1453) } \\
\text { Andreu Rafat (1453-...) }\end{array}$ & \multirow{3}{*}{ San Salvador } & \multirow{3}{*}{$\begin{array}{l}\text { Pere Cardona (...-1455) } \\
\text { Joan Berenguer (1455-1460) (unido } \\
\text { al beneficio anterior) }\end{array}$} \\
\hline San Jaime (PB) & Domènec Sibil & & \\
\hline \multirow[t]{2}{*}{ San Jaime y San Antonio } & \multirow{2}{*}{$\begin{array}{l}\text { Ramon Rossell (...-1450) } \\
\text { Manuel de Huesca (1450-1459) } \\
\text { Llorenç Vallterra (1459-...) }\end{array}$} & & \\
\hline & & San Saturnino (San Marcos?) & \begin{tabular}{|l} 
Joan Aragonès (1447-1453) \\
Antoni Cases (1453-...)
\end{tabular} \\
\hline \multirow[t]{2}{*}{ San Jaime y Santa Salomé } & \multirow{2}{*}{\begin{tabular}{|l} 
Joan Vacarices (...-1449) \\
Manuel d'Argentona
\end{tabular}} & San Valerio (PB) & Bernat Coffita \\
\hline & & San Vicente & Llorenç Giner (...-1452) \\
\hline \multirow[t]{2}{*}{ San Jerónimo y San Pedro } & \multirow{2}{*}{$\begin{array}{l}\text { Guillem Balanyat (...-1452) } \\
\text { Cristòfor de Guimerà (1452-...) }\end{array}$} & & Joan Pedrós (1452-...) \\
\hline & & San Victoriano & Joan Fontdevila (...-1455) \\
\hline San Jorge (PB) & Joan Ermengol & & Joan Companyó (1455-...) \\
\hline \multirow[t]{2}{*}{ San Juan $\left({ }^{*}\right)$} & \multirow{2}{*}{$\begin{array}{l}\text { Ramon Ciuraneta (...-1455) } \\
\text { Guillem del Camp (1455) } \\
\text { Guillem Bastut (1455-1461) } \\
\end{array}$} & Santa Ana & $\begin{array}{l}\text { Guillem Antich (...-1455) } \\
\text { Nadal Pelegrí (1455-...) } \\
\end{array}$ \\
\hline & & Santa Ana & Antoni Pasqüet \\
\hline San Juan (PB) & Bartomeu Baster & Santa Bárbara & Miquel Sagrera (...-1457) \\
\hline San Juan (PB) & Bernat Roig & & Pere Llaurador (1457-...) \\
\hline San Juan (PB) & Pere Florensa & Santa Bárbara & Joan Cortadelles (1448-1457) \\
\hline San Juan ante Portam Latinam & Arnau Porta & & Antoni Miquel Cardona (1457-...) \\
\hline San Juan Bautista & \begin{tabular}{|l|} 
Antoni de Barbarroja (...-1454) \\
Antoni Pasqüet (1454-1460) (unido al \\
beneficio de Santa Ana)
\end{tabular} & Santa Catalina $(*)$ & \begin{tabular}{|l|} 
Manuel Terrós (1446-1449) \\
Pere Terrós (1449) \\
Manuel Terrós (1449-...) \\
\end{tabular} \\
\hline \multirow{2}{*}{$\begin{array}{l}\text { San Juan, degollado, y San } \\
\text { Lorenzo }\left({ }^{*}\right)\end{array}$} & \multirow{2}{*}{\begin{tabular}{|l|} 
Bernat de Setcastella (...-1451) \\
Tristany Batlle (1451-...)
\end{tabular}} & Santa Cecilia & Hug de Sant Jordi (1452?-...) \\
\hline & & Santa Cecilia y Clemente & Nicolau Antoni de Vic (...-1451) \\
\hline \multirow[t]{2}{*}{ San Juan, evangelista $(*)$} & \multirow{2}{*}{\begin{tabular}{|l} 
Antoni Guany (1447-1451?) \\
Vacante por litigio (1451-1455) \\
Nicolau Olives (1455-...) \\
\end{tabular}} & & Antoni de Santafé (1451-...) \\
\hline & & Santa Eulalia & \begin{tabular}{|l|} 
Bernat Tutzó (...-1454) \\
Berenguer Miquel Cardona (1454-...) \\
\end{tabular} \\
\hline \multirow[t]{3}{*}{ San Juan, evangelista } & \multirow{3}{*}{$\begin{array}{l}\text { Jaume Arrufat (...-1454?) } \\
\text { Arnau Porta (1454-...) (unido al } \\
\text { beneficio de San Juan ante Portam } \\
\text { Latinam) }\end{array}$} & Santa Eulalia $(*)$ & Jaume Ardiaca (1454) \\
\hline & & Santa Eulalia (PB) & Hug de Sant Jordi \\
\hline & & Santa Inés & \begin{tabular}{|l|} 
Pere Coll (1448-1454) \\
Jaume Vilagrassa (1454-...) \\
\end{tabular} \\
\hline San Judas (PB) & $\begin{array}{l}\text { Joan Pedrós (unido al beneficio de } \\
\text { San Vicente?) }\end{array}$ & Santa Lucía & $\begin{array}{l}\text { Berenguer Domingo }(\ldots-1456) \\
\text { Mateu Joan Berga }(1456-\ldots) \\
\end{array}$ \\
\hline San Lázaro & $\begin{array}{l}\text { Pere Barrisca (...-1450) } \\
\text { Nicolau Claverol (1450-1451) }\end{array}$ & Santa Margarita (PB) & Pere Riera \\
\hline & Antoni Roig (1451-...) & Santa María & \begin{tabular}{|l} 
Pere Cabray (...-1458) \\
Pere Roig $(1458-\ldots)$
\end{tabular} \\
\hline San Lázaro & $\begin{array}{l}\text { Guillem de la Móra (...-1450) } \\
\text { Pere de Valldepérez (1450-...) }\end{array}$ & Santa María (PB) & \begin{tabular}{|l|} 
Pere Rolg (1458-...) \\
Guillem Esteve \\
\end{tabular} \\
\hline San Lorenzo, mártir $(*)$ & Esteve Borrell (...-1452) & \begin{tabular}{|l|} 
Santa María (PB) \\
\end{tabular} & Martí Juan \\
\hline & Llorenç Giner $(1452-\ldots)$ & Santa María (PB) & Tristany Vall \\
\hline San Lucas (Santa Lucía?) & Bernat Juan (...-1457) & Santa María y Salomé (PB) & Manuel Argentona \\
\hline & Bernat Baget $(1457-\ldots)$ & Santa María la Antigua & Miquel Urgellès (...-1450) \\
\hline $\begin{array}{l}\text { San Marcial y San Miguel en el } \\
\text { Palacio Episcopal }\end{array}$ & \begin{tabular}{|l|} 
Antoni Guany (...-1451) \\
Mateu Seyol (1451-1452) \\
Bernat Roig (1452-1453) \\
Francesc Vaquer (1453-...) \\
\end{tabular} & & $\begin{array}{l}\text { Pere Muñoz (1450-1451) } \\
\text { Llorenç de Vallterra (1451) } \\
\text { Tristany Batlle (1451) } \\
\text { Bernat (o Berenguer) de Setcastella } \\
(1451-. .)\end{array}$ \\
\hline San Marcos, evangelista & Bernat Carnicer & Santa María la Antigua (PB) & Joan Agramunt \\
\hline San Martín & Andreu Soler (1446-1462) & & \\
\hline San Mateo & \begin{tabular}{|l} 
Ferrer de Vilanova \\
Joan de Cardona (1449-1461)
\end{tabular} & $\begin{array}{l}\text { Santa Marla la Antigua Y } \\
\text { Expectación del Parto de María }\end{array}$ & Arnau Pinyol (1452-...) \\
\hline San Matías, apóstol & $\begin{array}{l}\text { Marc de Riglós (...-1449) } \\
\text { Bartomeu Sunyer (1449-...) }\end{array}$ & Santa María Magdalena & $\begin{array}{l}\text { Joan Parellades (...-1449) } \\
\text { Tomás de Lleida (1449-...) }\end{array}$ \\
\hline San Miguel (PB) & Francesc Vaqué & Santa María Magdalena (PB) & Pere Ferrer \\
\hline San Miguel (PB) & Joan de Setcastella & $\begin{array}{l}\text { Santa María Magdalena en les } \\
\text { Borges Blanques }(*)\end{array}$ & \begin{tabular}{|l} 
Montserrat Botella (...-1457) \\
Ramon de Cardona (1457-...)
\end{tabular} \\
\hline San Nicolás & $\begin{array}{l}\text { Jeroni de Santafé (1447-1450) } \\
\text { Manuel de Montsuar (1450-...) }\end{array}$ & Santa Marta $(*)$ & $\begin{array}{l}\text { Pere de la Naga (...-1454) } \\
\text { Llorenç Balaguer (1454-...) } \\
\end{array}$ \\
\hline San Pablo (PB) & Pere Florensa & Santa Marta & Guillem Ximeno (1447-1450) \\
\hline San Pedro y Santa Inés $(*)$ & \begin{tabular}{|l|} 
Bernat Pelegrí (1454-1458) \\
Bernat Pelegrí (1458-...) \\
\end{tabular} & & $\begin{array}{l}\text { Llorenç de Balaguer (1450-1456) } \\
\text { Martí Juan (1456-...) }\end{array}$ \\
\hline
\end{tabular}




\begin{tabular}{|l|l|}
\hline Santa Marta $\left(^{*}\right)$ & $\begin{array}{l}\text { Gabriel Esteve }(. .-1451) \\
\text { Pere Cuera (1451-1454) } \\
\text { Bernat Torroda (1454-1458) } \\
\text { Joan Ribelles (1458-...) }\end{array}$ \\
\hline Santa Tecla $\left(^{*}\right)$ & $\begin{array}{l}\text { Bernat Barquer (...-1455) } \\
\text { Martí Bendit (1455-...) }\end{array}$ \\
\hline Santa Tecla (PB) & Joan Bordell \\
\hline Santas Cruces (PB) & Miquel Valero \\
\hline $\begin{array}{l}\text { Santísima Trinidad y San Tomás } \\
\text { (PB) }\end{array}$ & Pere Picó \\
\hline Santo Domingo & $\begin{array}{l}\text { Jaume Ferrer (...-1450) } \\
\text { Mateu Pere Gavaldà (1450-1459) } \\
\text { Cristòfor Benet (1459) } \\
\text { Cristòfol Muntanyà (1459-1461) }\end{array}$ \\
\hline Santo Espíritu (PB) & Bernat Noguer \\
\hline Santo Tomás de Aquino $\left(^{*}\right)$ & Simó Pelegrí (1459-...) \\
\hline
\end{tabular}

\section{Bibliografía}

Agúndez San Miguel, L. 2014. "Carreras eclesiásticas y redes clientelares en la Castilla bajomedieval: la provisión de beneficios menores en el cabildo de la catedral de Burgos (1456-1470)». Anuario de Estudios Medievales 44/2: 665-687.

Alonso García, G. 1979. «Capillas, altares, imágenes, capellanías, presbiteriados y beneficios de la Seu Vella de Lleida desde su fundación hasta su cierre». Ilerda 40: 57-88.

Álvarez Palenzuela, V. Á. 1984. El Cisma de Occidente. Madrid: Rialp.

Barrio Gozalo, M. 2011. El sistema beneficial de la Iglesia española en el Antiguo Régimen (1475-1834). Alicante: Publicaciones Universidad de Alicante.

Bertran i Roigé, P. 1991. «L’Església de Lleida en el pontificat de Calixte III», en X. Company i Climent (ed.), Els Montcada i Alfons de Borja a la Seu Vella de Lleida: 91-103. Lleida: Amics de la Seu Vella.

Borau i Morell, C. 1993. «El sistema beneficial a la Seu de Barcelona: fundadors, advocacions i finançament artístic durant el segle XV». Pedralbes: revista d'història moderna 13/2: 139-147.

Borau i Morell, C. 2003. Els promotors de capelles i retaules a la Barcelona del segle XIV. Barcelona: Fundació Noguera.

Bover de Rosselló, J. M. a 1838. Memoria biográfica de los mallorquines que se han distinguido en la antigua y moderna literatura. Palma: Imprenta Nacional de Juan Guasp.

Busqueta i Riu, J. J. 2000. "La senyoria dels Sant Climent de Lleida: domini fluvial i proveïment a la Baixa Edat Mitjana», en E. Vicedo Rius (ed.), Terra, aigua, societat i conflicte a la Catalunya occidental: 81-102. Lleida: Pagès editors.

Busqueta i Riu, J. J. 2011. Manuel de Montsuar. Contra l'autoritarisme. Lleida: Alfazeta.

Canellas López, Á. 1954. El Reino de Aragón en los años 1410-1458. Palma: Diputación Provincial de Baleares.

Carbonell Boria, M.a J. 1998. "El beneficio eclesiástico en la ciudad de Valencia (primera mitad del siglo XIV)». Anuario de Estudios Medievales 28: 729-756.

Conejo da Pena, A. 2009. "Oligarquia ciutadana i promoció artística: la petjada dels Montsuar (c. 1350-1500)», en M. R. Terés Tomàs (coord.), Capitula facta et firmata. Inquietuds artístiques en el quatre-cents: 329-373. Valls: Cossetània edicions.

Cossé, J. y Lladonosa i Pujol, J. 1982. La nissaga dels Montsuar. Lleida: Institut d'Estudis Ilerdencs.

Cruselles Gómez, J. M.. 1992. «Los juristas valencianos en la Italia renacentista. Estudiantes y cortesanos». Revista d'Història Medieval 3: 143-160.

Diago Hernando, M. 2011. «El factor religioso en la actividad política y social de los linajes de la alta nobleza en la región soriana a fines de la Edad Media». Hispania Sacra 127: 7-39.

\begin{tabular}{|l|l|}
\hline Santo Tomás, mártir & $\begin{array}{l}\text { Bernat Sala (...-1453) } \\
\text { Francesc Morelló (1453-...) (unido al } \\
\text { beneficio de la Asunción de María) }\end{array}$ \\
\hline Santo Tomás $\left(^{*}\right)$ & Antoni Agullana (...-1461) \\
\hline Santos Inocentes & $\begin{array}{l}\text { Pere Peyns (...-1457) } \\
\text { Llorenç Ferrer (o Forner?) (1457-...) }\end{array}$ \\
\hline Santos Simón y Judas (PB) & Pere d’Orcuja \\
\hline Todos los Santos & $\begin{array}{l}\text { Berenguer Ferrer (...-1451) } \\
\text { Miquel Pasqual (1451-1459)? } \\
\text { Pau Cardona (1459-...) }\end{array}$ \\
\hline Todos los Santos & $\begin{array}{l}\text { Pere Riber (...-1452) } \\
\text { Lluís Rossell (1452-1456) } \\
\text { Rafel Calç (1456-1459) } \\
\text { Miquel Sallent (1459-...) }\end{array}$ \\
\hline Todos los Santos (PB) & Miquel Albesa \\
\hline
\end{tabular}

Ferrer Mallol, M.a T. 1992. «Un memorial de greuges de la mà menor de Lleida contra la mà major (s. XV)», en Miscel-lània homenatge a Josep Lladonosa: 293-314. Lleida: Institut d'Estudis Ilerdencs.

García García, A. 2002. «La organización de los estudios jurídicos», en J. J. Busqueta i Riu y J. Pemán Gavín (coords.), Les universitats de la Corona d'Aragó, ahir i avui. Estudis històrics: 53-71. Barcelona: Pòrtic.

Gayà Massot, R. 1950. Los valencianos en el Estudio General de Lérida. Valencia: CSIC, Patronato "José María Quadrado».

Guijarro González, S. 2008. "Jerarquía y redes sociales en la Castilla medieval: la provisión de beneficios eclesiásticos en el cabildo de la catedral de Burgos (1390-1440)». Anuario de Estudios Medievales 38/1: 271-299.

Guinot Rodríguez, E. 1999. Els fundadors del Regne de València. Repoblament, antroponímia i llengua a la València medieval. Valencia: E. Climent, editor.

Le Goff, J. 1989. El nacimiento del Purgatorio. Madrid: Taurus.

Lladonosa i Pujol, J. 1944. La antigua parroquia de San Martín de Lérida. Lleida: Artes Gráficas Ilerda-P. Guimet.

Lladonosa i Pujol, J. 1962. Manuel de Montsuar, president de Catalunya. Barcelona: Rafael Dalmau, editor.

Lladonosa i Pujol, J. 1976. Relacions entre Mallorca i Lleida a l'època medieval. Barcelona: Rafael Dalmau, editor

Mercati, A. 1919. Raccolta di concordati su materie ecclesiastiche tra la Santa Sede e le autorità civili. Roma: Tipografia Poliglotta Vaticana.

Pérez González, S. M.a 2012. «Los beneficios parroquiales: un acercamiento al estudio del clero secular». Hispania Sacra 130: 497-523.

Pleyán de Porta, J. 1873. Apuntes de historia de Lérida, ó sea compendiosa reseña de sus mas principales hechos desde la fundacion de la ciudad hasta nuestros tiempos, con noticias de sus monumentos, de su universidad y varones ilustres que han florecido en ella, de los escritores leridanos, asi como tambien de su comercio, industria y agricultura, usos y tradiciones populares. Lleida: Imprenta de Carruez.

Rapp, F. 1973. La Iglesia y la vida religiosa en Occidente a fines de la Edad Media. Barcelona: Editorial Labor.

Rodríguez Llopis, M. y García Díaz, I. 1994. Iglesia y sociedad feudal. El Cabildo de la Catedral de Murcia en la baja edad media. Murcia: Universidad de Murcia.

Strnad, A. A. 1979. "Cerdá y Lloscos, Antonio», en A. M. Ghisalberti (dir.), Dizionario Biografico degli Italiani: XXIII, 704-706. Roma: Instituto dell'Enciclopedia Italiana.

Tejada y Ramiro, J. 1862. Colección completa de concordatos españoles. Madrid: Imprenta de D. P. Montero.

Zaragoza i Pascual, E. 2004. Història de la congregació benedictina claustral tarraconense (1215-1835). Barcelona: Publicacions de l'Abadia de Montserrat. 